\title{
Evaluation tools within the European Higher Education Area (EHEA): An assessment guide for evaluating the competences of the Final Year Project in the social sciences
}

Joan Mateo $^{1}$, Anna Escofet ${ }^{2}$, Francesc Martínez-Olmo ${ }^{3}$, Javier Ventura ${ }^{4}$ \& Dimitrios Vlachopoulos ${ }^{5}$

This is a preprint version of Mateo, J., Escofet, A., Martínez-Olmo, F., Ventura-Blanco, J., \& Vlachopoulos, D. (2012). Evaluation Tools in the European Higher Education Area (EHEA): an assessment for evaluating the competences of the Final Year Project in the social sciences. European Journal of Education, 47(3), 435-447. article. http://doi.org/10.1111/j.1465-3435.2012.01536.x

\section{Abstract}

The guidelines of the European Higher Education Area (EHEA) imply the rethinking of many of the current evaluation systems, since the new pedagogical models are now focused on the learning acquired through the students' personal work and on the establishment of the ideal conditions for them to achieve the learning outcomes of the proposed educational objectives. In this context, it has been a standard practice during the last years for social sciences undergraduate programs to incorporate at least one major assessment exercise in the final (fourth) year of the studies in the form of a

\footnotetext{
${ }^{1}$ Professor, Faculty of Pedagogy, University of Barcelona, 171 Vall d'Hebron Ps., Migdia Building, 08035, Barcelona. Email: jmateo@ub.edu.

${ }^{2}$ Associate Professor, Dean of the Faculty of Pedagogy, University of Barcelona, 171 Vall d'Hebron Ps, Migdia Building, 08035, Barcelona. Email: annaescofet@ub.edu.

${ }^{3}$ Associate Professor, Research director at the Institute of Education Sciences, University of Barcelona, 171 Vall d'Hebron Ps., Migdia Building, 08035, Barcelona.Email: fmartinezo@ub.edu.

${ }^{4}$ Associate Professor, Head of pedagogy undergraduate program, University of Barcelona, 171 Vall d’Hebron Ps., Migdia Building, 08035, Barcelona. Email: jventura@ub.edu.

${ }^{5}$ Postdoctoral Research Associate, Faculty of Education, Autonomous University of Barcelona, G Building, Office 256, UAB Campus, 08193 Bellaterra. Email: dimitrios.vlachopoulos @uab.cat.
} 
project. This "Final Year Project" introduces a new problem-solving situation in undergraduate programs, and students have to use their initiative to identify the research problems, decide on the information they need and how to obtain it, use the collected information to solve the research problems and present the results in an adequate way. This paper presents an efficient and objective guide for the assessment process of the Final Year Project (FYP) in social sciences, which can easily be customized for different social sciences curricula. More analytically, the guide, which has been developed to help higher education institutions create their own FYP assessment systems, starts with the definition of the final year project and the description of the structure that has to be followed for its realization, continues with the analysis of its competences and their assessment, and ends with a proposal for implementation of the assessment procedure and the role of the evaluation agents.

Keywords: Final Year Project, assessment, social sciences, evaluation, European Higher Education Area.

\section{Introduction}

During the last decade, analyses, studies and debates on the Bologna Process and its implementation in the European higher education institutions have grown. If we realize a literature review we will notice that in Europe alone, references are already in their thousands, whilst in other regions of the world (and especially in Latin America) this phenomenon is being observed with attention, although its impact varies from one country to another (Tiana Ferrer, 2010).

The guidelines of the European Higher Education Area (EHEA) imply the rethinking of many of the current evaluation systems, aiming, at a certain degree of convergence and 
unification of the European higher education systems. The signatories have committed themselves to coordinate their higher education policies in order to increase the international competitiveness of the European system of higher education, enhance cooperation between universities in order to help them to develop their potential and thus achieve substantial economies, favour student mobility and improve access to various kinds of study programs (Malan, 2004). Of course, it is easy to understand that as teaching and learning methods are becoming more heterogeneous, the measurement of the general competences seems to be still rather difficult and the assessment methods need much development (Fretwell, 2003).

A general trend is that curriculum guidelines shift from being content-oriented to being learning-oriented and individuals are seen as self-regulated in their approach to knowledge and the curriculum and although many nations create their own guidelines, they are changing with global demands (Rosenmund, 2006; Karseth \& Sivesind, 2010). The new pedagogical models are now focused on the learning acquired through the students' personal work and on the establishment of the ideal conditions for them to achieve the learning outcomes of the proposed educational objectives. The new era of Higher Education requires the establishment of a comprehensive quality assurance system at every European educational institution. As part of this new system, universities and programs must demonstrate that their graduates have achieved a set of learning outcomes established in each discipline area.

After studying the literature about assessment and evaluation in the European Higher Education Area, we were able to understand that numerous terms have been used to describe the results of the learning processes, such as abilities, skills, capacities, competences, etc., either as synonyms or as words with different nuances. 
In this context, we felt the need, before presenting our research, to clarify some terms related to the concept of "competence" (Mateo, Escofet, Martínez \& Ventura, 2009):

- Traits and personal characteristics are an innate base of learning, from which we can build subsequent learning experiences. The differences in traits and features help us explain why people choose different learning experiences and acquire different levels and types of knowledge and skills.

- Knowledge, skills and attitudes are being developed from the different learning experiences, which can include -if defined broadly- the school, the work, the family, the social participation, etc.

- Competences are a combination of knowledge skills and attitudes acquired by the learner. They are developed through integrative learning experiences in which knowledge and skills interact with the aim to give an efficient response to the executed tasks.

- Demonstrations involve the application of the acquired skills in specific contexts.

The following figure shows the hierarchical structure of these concepts and allows us to understand their differences*. 


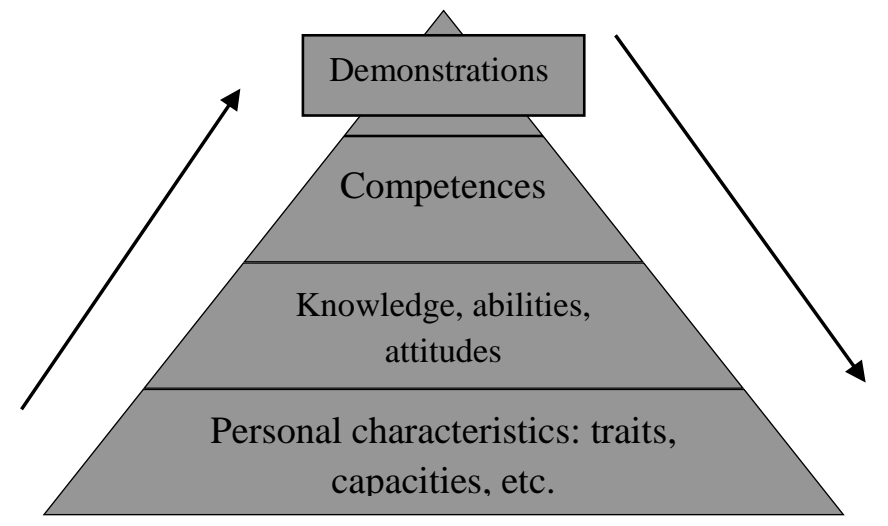

Performance

Integration

Knowlwdge

Foundations

Figure 1: The hierarchical structure of the terms related to the concept of competence.

According to Weinert (2001), competence acquisition is more than gaining a skill on a domain/ discipline. This process also involves regulating, monitoring and initiative in the use and development of the skills. The acquisition of competences, in the sense of development of knowledge and abilities, also involves interaction, mediation and management between the knowledge and the reality (physical, social or cultural) and demands an effective action for the interpretation of the learning context. Moreover, an adequate use of knowledge and abilities includes knowing what you need to know and what you don't need to know. Reaching this kind of knowledge means recognizing the context in which the abilities are being developed. Finally, the possession of a specific ability simply means to dispose of a concrete tool that helps you interact in a very concrete context, while the competence acquisition adds a direct effect on our ability to interpret and give a new meaning to the reality in which we operate.

As a summary we can say that:

- The competence is a combination of skills, attitudes and knowledge, necessary to perform a task effectively.

- The competences can be demonstrated in action and, therefore, can be evaluated only by activities that involve their implementation. 
- The competences can be acquired and developed through activities that integrate skills, attitudes and knowledge that has been acquired in an earlier stage, and maybe separately.

In this context, it has been a standard practice during the last years for social sciences programs to incorporate at least one major assessment exercise in the final (fourth) year of the studies in the form of a project. This Final Year Project is viewed as the culminating learning experience of the undergraduate program, and the quality of student output is often used as an indicator of the quality of the program as a whole (Jawitz, Moore \& Shay, 2002). It is important to mention that the FYP has been well studied in natural sciences and engineering (Orsmond, Merry and Reiling, 2004), where it has become a major component of the departments' curricula (Vitner and Rozenes, 2009). We cannot find extensive research on this topic in social sciences.

More analytically, most social sciences university departments in Europe follow a system of two semesters per year for 4 years. Students have to complete at least five courses per semester - 40 courses in total over four years. These courses consist of three categories of core, major and elective subjects. Students enrolled in their final year of studies are required to undertake and complete a research project, which lasts at least 6 months. Students may select a research project from a list offered by academic staff or may suggest their own topic based on individual interest (Ku and Goh, 2010). This last year of undergraduate studies is rather less conventional in character. It is this part of the degree that is most strongly oriented towards student project work and which makes it appropriate for the degree title to include the description "by independent study" (Cuthbert, 1995). During this final year, students are expected to complete an individual project that will constitute between $20 \%$ and $50 \%$ of their final year program. This project is quite likely to be interdisciplinary in character and will frequently have an 
applied problem orientation. These projects are composed or interrelated component essays and are up to 20.000-30.000 thousand words in length. They are likely to include practical work, such as surveys, case-studies, co-relational researches and placements. Projects must develop out of the discipline areas which students have studied in the first three years of the degree.

According to Cuthbert (1995, p.268), such projects have frequently been seen as providing a first opportunity for students to gain initial experience of implementing research skills. For the best students, they would be seen as providing a basis on which postgraduate work could be developed. The current view of project work is probably much broader than this. It is seen as an important learning experience in itself and although it does provide important experience of research and inquiry skills, it also provides an opportunity for students to tackle problem areas that have "real world" as well as purely academic relevance. Project work can also provide an opportunity for students to have greater experience of working independently and managing their own progress.

By definition, project work introduces a new problem-solving situation in undergraduate programs, and students have to use their initiative to identify the research problems, decide on the information they need and how to obtain it, use the collected information to solve the research problems and present the results in an adequate way (Kuisma, 2007). The complexity of the Final Year project requires a well-defined process that facilitates the students in their completion of the tasks. Also, since independent study constitutes such a major part of the final degree year within the undergraduate programs in social sciences, considerable emphasis has been placed on preparing students to cope with the demands of working in this way from the inception of the degree. Our procedures for supporting students in the development of their ideas 
for their final year project have evolved gradually through the experience of the Bologna process applied in European universities during the last years.

This paper raises the need to generate a change in the evaluation process and to develop a systematic approach for the assessment procedure of the Final Year Project in social sciences, in order to help the higher education institutions create their own evaluation systems for this activity.

\section{Research context}

One of the most outstanding features of higher education in Spain in the last two decades has been the emergence of national and regional university evaluation and accreditation bodies and strategies. The need for better quality and control of education and the qualifications offered by universities led to the implementation of mechanisms generically designed for quality assurance (Tianna Ferrer, 2010).

In this context, in 1996 the regional government of Catalonia created the Catalan University Quality Assurance Agency (AQU Catalunya), a public entity with an internationally recognized status, whose mission is to assure the quality of higher education through compliance with European standards of quality and to safeguard of the interests of society in the quality of higher education. AQU's activity is developed through:

- Analytical external quality assurance processes (review and accreditation)

- International benchmarks and an innovation based perspective

- Transparency and publicity mechanisms 
- The involvement of the educational community and social stakeholders

- Competent people who are motivated and satisfied with the work carried out by the agency.

- Respect for some important values, such as fostering of cooperation, user orientation, proactivity, quality assurance, integrity, independence, accountability, efficacy and efficiency.

Since the beginning of the European convergence process in higher education, the main goal of the Catalan University Quality Assurance Agency (AQU Catalunya) was to provide Catalan universities with the necessary tools that could facilitate this process, such as the Pilot plan for the adjustment of their degrees to the European Higher Education Area (EHEA) or the document Tools for the adjustment of the university degrees to the Higher Education Area (AQU, 2005). Along the same line of thought, in 2007, AQU Catalunya announced a call for the design and development of evaluation guides about the competences that should be acquired by the undergraduate students during their studies. This initiative was based on two main facts. First, all the adjusted degrees had to focus on the competence acquisition. This means that they should explain clearly what they expect from their graduates in terms of transversal and specific competences. Secondly, the European standards for quality assurance (ENQA, 2009) underline that the students need to receive detailed information about the assessment methodology and the criteria that will be applied in order to measure their performance, knowledge and efficiency. Until now, these two facts have been a challenge for the university instructors, who are trying to find out how to develop and evaluate consistently the competences that are associated with the different disciplines and programs. 
Moreover, in a context of greater autonomy concerning the degrees' planning and development, the academics -not only in Catalonia, but also at an international levelare focused on the certification of the students' achievements, and the evaluation of their knowledge is the most adequate moment to confirm their achievements.

The aim of these guides was to offer the academic instructors some important resources of references and examples that could allow them to design, in coherence with the academic profile of each program and the main objectives of each discipline, the strategies of the students' assessment.

After the establishment of the above theoretical framework, one of the main tasks of the Agency was to prepare an assessment guide for the Final Year Project in social sciences undergraduate studies in order to be customized for different social sciences curricula and help both students and instructors understand its idiosyncrasy and importance. Our research group was chosen to carry out this project and create some evaluation guidelines related to the global demands of the European Higher Education Area.

\section{The definition of the Final Year Project (FYP)}

Before developing our evaluation plan for the Final Year Project in social sciences, we consider it necessary to identify its fundamental characteristics and to define it according to the guidelines of the European Higher Education Area.

Firstly, it is important to mention that, until lately, there was no tradition of preparing research projects at the end of the social sciences undergraduate programs, even though the students had to elaborate smaller projects in the context of the methodological courses and to realize exhaustive bibliographical researches on a concrete topic. In addition, some of the social sciences undergraduate programs had established some 
curricular practices, which can be considered as a final project of the studies if they are officially documented and reported. Nevertheless, none of the above three activities coincides with the concept of the FYP as it was described within the EHEA.

Under the system resulting from the process of adaptation to the European Higher Education Area, the Final Year Project becomes a key aspect of the programs' curriculum and has to be oriented to the development of a research or an innovation in the professional camp of the students. Since this project is considered the most complete and important evidence of research or innovation presented by the students, it is planned to play an important role in the final grade of the students. In addition, the FYP offers opportunities to the students for their personal and academic development and can also facilitate their professional integration in the labor market after completing their studies.

Through the FYP, the students have to integrate and apply-with professional, creative and innovative criteria- the competences acquired during these four years of university studies; they have to incorporate new ones, which are related to the FYP itself, such as autonomy, initiative, knowledge development, abilities and strategies; and to give solutions to the research problems that derive from the project.

It is obvious that the concrete characteristics of the Final Year Project will be different among the various programs, according to their academic priorities and the professional profile that they would like to give to their students. While these projects may vary greatly in scope and nature (e.g., requiring a large-scale written assignment such as a dissertation or extended essay or the design and production of some type of artifact) must share a number of key characteristics (Todd, Bannister \& Clegg, 2004). 


\section{A protocol for the evaluation of the Final Year Project}

There is widespread agreement among writers on assessment in higher education that the production, publication and discussion of clear assessment criteria are a sine que non of an effective assessment strategy (Woolf, 2004).

In this context, we present a protocol, which is designed as a general guide-not only for the tutor of the FYP but also for the students-in order to achieve a double objective:

a) One the one hand, to facilitate the regulation and the conceptualization of the things that need to be done during the elaboration of the FYP by offering ongoing support during the whole process.

b) On the other hand, to use it as an evaluation instrument to facilitate the qualification (grading) of the students.

In order to identify the basic characteristics of this guide, we realized a comparative analysis of relevant core policy documents and curriculum guidelines produced by different European universities, including the Magdeburg-Stendal University (Baumgarten and Hartmann, 2008), the Technische University of Dresden (2007), the Reinisch-Westfalische Hochschule Aachen University (Biegi, 2008), the Freie University of Berlin (2008), the University of Limerick (2003), the Kirchiliche Padagogische Hochschule of Wien (2007), the University of Bath (Harris and Smith, 1983), the Oxford Brookes University (Webster, Pepper and Jenkins, 2000) and the School of Engineering of the United Kingdom (2002). 


\section{The FYP structure}

Our guide has divided the elaboration process of the Final Year Project into five phases considered to be the five most important moments of the project's development:

a) Topic selection

The selection of a topic is one of the most complex tasks during the elaboration process of the FYP. The ability to formulate significant research questions implies an important grade of personal maturity, knowledge of the application context and control of the contents involved in the study.

b) Work plan

Once the topic is selected, it is important to plan in detail the stages of the project. During this phase it is necessary to determine the basic elements and organize them in a clear and detailed manner providing a systematic guide for working on the project.

c) Development

This phase is fundamental, since the student has to demonstrate that he/she is capable of resolving the research problem of the project. This implies the contextualization of the project in its theoretical framework, the establishment of clear objectives to be achieved, the realization of an empirical approach - the collection of the necessary information, its analysis and interpretation and, of course, the extraction of the corresponding conclusions.

d) Delivery and public presentation

During this fourth phase, the communicative competences of the students should be activated in order to explain, in written form, all the research activities that have taken 
place in the FYP and to present them, orally, before an invited public. This public presentation should provoke a debate in which the student has to emphasize the most essential aspects of the project and to justify the most complex and conflictive ones. This procedure demands, among other things, a deep understanding of the knowledge involved, communication skills, emotional control and mental acuity.

e) Evaluation, improvement and future prospective

Finally, we consider that it is important for the students to realize a self-evaluation as a tool of critical thinking. In this context, a metacognitive level has to be generated about the research activities and the methodology followed in order to develop the capacity to learn how to learn. The analysis of the FYP has to permit the improvement of the students in the context of the development of their work.

The above presentation of the structure that has to be followed for the realization of the FYP shows clearly that the last two phases are fundamental, since it is impossible to confirm whether the students have acquired the necessary knowledge and competences without them. Of course, each phase is very important, since they all activate various fundamental competences that, though they are not exclusive to the FYP, can, in the context of the project be developed and reflected on.

\section{Competences, learning results and evaluation standards for the FYP}

One of the most important activities during the evaluation of competences is to distinguish the term "competence" from the term "learning result", since the learning results are the elements that permit the visualization of the competences. 
The identification of the competences associated with the FYP is made through the descriptors of Dublin (Joint Quality Initiative, 2004), which helped us obtain a list of 17 competences:

- Identification of a topic.

- Realize a literature review on a specific topic.

- Establish questions or objectives that can orient the project.

- Identify and organize the fundamental elements of the FYP.

- Distinguish the different phases of the FYP.

- Present and defend in public the progress report to an evaluation committee and/or a group of students.

- Select the fundamental sources for the construction of the bibliography of the project.

- Integrate the necessary knowledge to create the theoretical framework of the project.

- Collect, analyze and interpret the obtained data.

- Demonstrate control over the technical language of the field.

- Demonstrate ability to communicate- in both oral and written form- in at least two languages (mother language and English).

- Develop a correct and adequate report to be orally communicated.

- Get in touch with expert audiences. 
- Identify the most important aspect of the project.

- Interpret rigorously the information obtained.

- Respond to the demands of the expert audiences.

- Be aware of the process of the FYP realization by generating new knowledge.

For our research group "a student has acquired a competence when she/he can demonstrate sufficient evidence of learning results related to this competence". We are aware that three basic hazards lurk from the above thesis:

a) Error in representation: the chosen results are not representative of the competence.

b) Insufficient representativeness: the results are representative, but some important ones are missing.

c) Lack of intensity in the results' achievement: all the important learning results are present but they haven't been achieved with the necessary intensity in order to confirm the achievement of the competence.

Due to this last hazard, we consider it very important to raise the issue of "evaluation standards". The determination of an evaluation standard consists of the establishment of the level that has to be achieved, a group of learning results, in order to confirm that the competence associated with them has been acquired. The determination of these standards can be explicit, by trying to describe - - in an exhaustive way - the level of achievement that we consider sufficient in order to confirm if the presented evidence corresponds or not to these established requirements. It can also be implicit, by associating an evaluation scale to every learning result and letting the evaluation experts 
decide the required level of intensity that is needed to achieve this result in order to confirm the acquisition of the associated competence. At this point, we consider it necessary to identify the significance of each category of this evaluation scale and to establish the minimum level of achievement for the competences.

\section{Application of the FYP}

Every phase of the Final Year Project responds to a different moment of the research activity and this is why it is important to evaluate every phase separately once it is finished. Since only the last phase has a transversal character and has to be applied in different moments during the realization project, we consider that an evaluation report should be filled in at the end of every phase, in order to register some improvement strategies related to this phase.

Moreover, it is important that the students, apart from the FYP documents, to develop and apply a sort of systematic registration, which could permit the classification and storage of all the data they produced during the realization of the Final Year Project (evaluation reports of their tutor, consulted documents, modifications, reflections, etc.). This registration would be a negotiation between the tutor and the students in order to identify the necessary documents to be delivered at the end of the project. In this phase, the tutor needs to define and explain to the student what is meant by issues such as transparency of assessment, meaningful feedback, open discussion and explicit marking criteria (Orsmond, Merry and Reiling, 2004).

In order to be able to proceed with success in the realization of their FYP, the students have to obtain a "minimum" level in all the evaluable parts of the project. For example, 
in a scale from 1 to 4 ( 1 = excellent, 4 = very poor $)$, it would be necessary to obtain at least 3. Also, it is always fruitful, along with the score of every part, to add some improvement proposals for the students, so this guide could work as an assessment instrument that aims toward the optimization of the project. In any case, the formulation of these proposals has a voluntary character when the evaluated parts have obtained 1 or 2 and it is obligatory when the evaluated part has obtained 4. It depends on the tutor whether it is needed to add some proposals for modification or not when the result of the evaluated part is 3 .

The School (Faculty), through its quality assurance mechanisms, needs to establish agents and procedures to avoid or resolve any possible conflict situations derived from the above regulation.

\section{Evaluation (grading) of the FYP}

Our research group considers the concept of "grade" to be the association of a quantitative category with a judgment/opinion. As far as our guide is concerned, we are interested to establish a sort of orientation that permits an easy adoption of the evaluation criteria and also respects the students' and tutors' rights. As was mentioned before, we consider that the different phases of the FYP should be examined separately.

More analytically, the third and the fourth phases, which are associated with the development of the Final Year Project and its presentation and public defense, constitute the most important nucleus of the whole activity. This doesn't mean that these are the most important parts of the project, but it is obvious that the final evaluation of the FYP depends more on them. In this context, the third and the fourth 
phase should be worth $30 \%$ (each) of the final grade of the project, and it should be obligatory for the students to obtain at least a grade of 3 in all the parts that can be modified and an average of 3 in the parts that cannot be modified. More concretely, in the third phase, which offers the possibility to the students to modify their work, the students have to obtain in all elements at least a grade of 3 . In the case of an oral presentation, the students would need a minimum average grade of 3 .

On the other hand, we consider adequate that the first and second phase should be worth a $20 \%$ of the final grade of the FYP (10\% each) and, since they can both be modified, we would require that the students obtain at least a grade of 3 in all its elements. It is logical that without an identification of a topic, and statement of its importance and significance (first phase), and without an acceptable work plan, the FYP cannot get an approval to continue with the next phases.

Finally, we consider that the last phase of the FYP, with its specific characteristics, is also a very important part of the process and this is why we give a $20 \%$ of the final grade in this part. Also, since it is a phase that can be modified, the students are obliged to obtain at least a grade of 3 in all its elements. During this phase we have introduced a self-evaluation process with the objective to make the students aware of the quality of their research projects. More concretely, the students are obliged to analyze their own work by evaluating it (with a concrete grade) and by justifying the principles applied during the self-evaluation. We have identified a double base for the evaluation of this process: On the one hand, the coincidence between the evaluation of the tutors and the self-evaluation of the students can be considered as a positive element but, on the other hand, we have to take into consideration mostly the quality of the reflections applied in order to justify the proposed grade by the student. 


\section{The evaluation agents}

In the implicit evaluation process we foresee the activity of four types of evaluation agents:

a) The students

The students act as agents during the self-evaluation process, which has an important influence on the determination of their final grade and aims to develop their capacity of self-analysis and metacognition, since only the students themselves know what learning has taken place and how they have been able to use the situations and tasks to further their knowledge and skills (Kuisma, 2007).

b) The tutor and the student

Both the tutor and the student participate in the evaluation of the preliminary presentation during the third and the fourth phase. They both do very useful brainstorming related to the modification and improvement of the work and prepare the student for the upcoming public presentation and defense.

c) The committee of experts

The committee of experts evaluates mostly the quality of the public presentation and defense of the FYP and the debate that is being produced from it. The main function of this committee is to judge the capacity of communication of the student and the way in which she/he presents the project to a qualified audience. In addition, the experts evaluate how the students defend their ideas, their emotional control, the resources they use for the presentation, and their receptivity to proposals for modification and improvement. 
d) The tutor

According to the guideline of the European Higher Education Area, the role of the tutor is fundamental for the success of the Final Year Project, since he/she becomes more a facilitator of learning opportunities than a knowledge transmission source. In this context, the tutors are administrating directly the $70 \%$ of the final grade of the FYP and maintaining the control throughout the whole process of the FYP. Finally, they also participate in the decision making of the experts committee, since they have negotiated with the students the whole evaluation and learning process.

\section{Conclusions}

After carrying out our research, we can separate its conclusions intro two categories. The first category is related to the theoretical framework and the context analysis of the research and the second is related to the preparation and design of the guide for the evaluation of the competences of the Final Year Project.

As far as the first category of conclusions is concerned, we can say that the learning processes in the undergraduate curricula involve both the acquisition of disciplinespecific knowledge and the development and reinforcement of professional skills. According to the new era of Higher Education, which requires the establishment of comprehensive quality assurance systems at every European educational institution, the realization process of the Final Year Project is a fundamental activity for the students' academic and personal improvement and their integration into the labor market. 
The introduction of the concept of competences in the university curricula allows a rapprochement between the academic world and the labour market. Also, the definition, development and testing of the acquisition of the competences give the opportunity to instructors and students for a more efficient learning process.

The traditional evaluation procedures (content examination) don't meet the requirements of the Bologna process and don't facilitate the new roles of the students (researchers, active participants in the teaching - learning process, autonomous, professionally prepared, etc.) within the European Higher Education Area.

The assessment approach has to be collective and shared. The Faculty, the centre or the institution has to make sure that the students receive an evaluation based on their competences, not only their final stage acquisition but also their development during the undergraduate studies. In the universities, the evaluation practice cannot continue having as a reference the subjects and the instructors (considered as individuals) but it has to consider all the subjects as a whole and the teaching staff from a transversal perspective (for example, which competences need to be worked in every degree year.

As far as the second category of conclusions is concerned, we can say that the preparation of our guide for the evaluation of the competences of the Final Year Project in social sciences has been a big challenge for our research team, since we had to proceed independently to risk drawing conclusions due to the limited amount of previous research in this field. In this context, we presented an approach to the definition of the Final Year Project by analysing all its important aspects within the European Higher Education Area and by explaining its specific characteristics in order 
to help the students and the tutors understand its role and basic functions within the undergraduates programs of social sciences.

We identified all the competences associated with the FYP in order to prove that they can play the role of a culminating learning experience in an undergraduate program in social sciences, since these competences are often used as an indicator of the quality of the students' learning and the quality of the academic programs as a whole.

In addition, we tried to explain the new functions of the teaching staff as tutors within the European Higher Education Area by emphasizing their active participation during the whole process of the realization of the FYP as "learning facilitators" through a continuous debate and negotiation with the students and not through "masterly lectures". These new functions were presented in all the phases of the FYP preparation (topic selection, work plan, delivery, evaluation, public presentation).

Finally, we identified some useful proposals for the evaluation of the Final Year Project, according to the evaluation of its associated competences. We consider that these proposals can be easily adapted to any social sciences curriculum and that they include all the necessary elements of the project for its final assessment. In this context, we also distinguished the different categories of evaluation agents within the FYP process and explained their function and importance in relation to every phase of the research activity.

We strongly believe that this paper opens a window for further debate on this field, which can help us improve our guidelines for the evaluation of competences of the Final Year Project through the exchange of similar research experiences and practices. 


\section{NOTES:}

** This concept derives from a study realized by the Council of the National Postsecondary Education Cooperative (NPEC) and its Working Group on competency-based Initiatives, sponsored by the National center for Education Statistics (NCES). Reference: NCES (2002). Defining and Assessing Learning: Exploring Competency-Based Initiatives. Available online at: www.inces.ed.gov/publicsearch/ [accessed 10 December 2010].

\section{References}

AQU (2005) Guia general per dur a terme les proves pilot d'adaptació de les titulacions a l'EEES. Titulacions de grau . Available online at: http://www.aqu.cat/publicacions/materia_metodologic_en.html (accessed 10 January 2011).

BAUMGARTEN, K. \& HARTMANN, T. (2008) Leitfaden zur Planung un Erstellung der Bachelorarbeit. Available online at: www.hs-magdeburg.de/fachbereiche/fsgw/studium/Gesundfm/Fragen/LEITFADEN_BACHELORARBEIT_03_2008.pdf (accessed 15 August 2010].

BIEGI, M. (2008) Leitfaden Bachelorarbeit fur Studierende. Available online at: www.ipw.rwth-aachen.de/ba/ba_leit_arbeit_tx.pdf (accessed 14 August 2010).

CUTHBERT, K. (1995) Project planning and the promotion of self regulated learning: From theory to practice. Studies in Higher Education, 20, pp.267-277. 
ENQA (2009) Standards and Guidelines for Quality Assurance in the European Higher Education Area. Available online at: http://www.enqa.eu/pubs_esg.lasso (accessed 12 January 2011).

JOINT QUALITY INITIATIVE (2004) Shared Dublin descriptors for the Bachelor's, Master's and Doctoral awards. Available online at: http://www.jointquality.nl/ (accessed 12 August 2010).

FREIE UNIVERSITAT BERLIN (2008) Leitfaden fur Bachelorarbeit und Prufungen an der Arbeitsstelle Kommunikationspolitik/ Medienokonomie. Available online at: www.Polsoz.fuberlin.de/kommwiss_institut/kommunikationspolitik/lehrmaterialien/allg emeines/Leitfaden_Bachelorpr_fung_2008.pdf (accessed 15 August 2010).

FRETWELL, D. (2003) A Framework for evaluating Vocational Education and Training. European Journal of Education, 38, pp. 290-300.

HARRIS, D. \& SMITH, B. (1983) Undergraduate Project Work. Assessment and Evaluation in Higher Education, 8, pp.246-261.

JAWITZ, J., MOORE, R. \& SHAY, S. (2002) Management and assessment of final year projects in engineering. The International Journal of Engineering Education, 18, pp. $472-478$.

KARSETH, B. \& SIVESIND, K. (2010) Conceptualising Curriculum Knowledge Within and Beyond the National Context. European Journal of Education, 45, pp. 103120. 
KIRCHLICHE PADAGOGISCHE HOCHSCHULE (2007) Leitfaden Bachelorarbeit.

Fahrplan zur Bachelorarbeit. Available online at: www.erpa.at/files/File/Leitfaden\%20 Bachelorarbeit.doc (accessed 14 August 2010).

KU, H. \& GOH, S. (2010) Final year engineering projects in Australia and Europe. European Journal of Engineering Education, 35, pp.161-173.

KUISMA, R. (2007) Portfolio assessment of an undergraduate group project. Assessment and Evaluation in Higher Education, 32, pp. 557-569.

MALAN, T. (2004) Implementing the Bologna Process in France. European Journal of Education, 39 (3), pp. 289-297.

MATEO, J., ESCOFET, A., MARTÍNEZ, F. \& VENTURA, J. (2009). Guía para la evaluación de competencias en el trabajo de fin de grado en el ámbito de las ciencias sociales y jurídicas. (Barcelona, Generalitat de Catalunya. Agència per a la Qualitat del Sistema Universitari a Catalunya).

ORSMOND, P., MERRY, S. \& REILING, K. (2004) Undergraduate project work: can directed tutor support enhance skills development? Assessment and Evaluation in Higher Education, 29, pp. 625-643.

ROSENMUND, M. (2006) The current discourse on curriculum change: a comparative analysis of National Reports on Education, in A. BENAVOT \& C. BRASLAVSKY (Eds.) School Knowledge in Comparative and Historical Perspective. Changing Curricula in Primary and Secondary Education. CERC Studies in Comparative Education 18, Comparative Education Research Centre, The University of Hong Kong (Hong Kong, Springer). 
SCHOOL OF ENGINEERING (2002) Project Handbook. Available online at: www.projectsquared.lboro.ac.uk/resources/project_handbook.doc (accessed 15 August 2010).

TECHNISCHE UNIVERSITAT DRESDEN (2007) Leitfaden fur das Exposé zur Bechelorarbeit. Available online at: www.tudresden.de/die tu_dresden/fakultaeten/ philosophische_fakultaet/ikw/stu/semap/ss07/reflexion/Exposee_anleitung.pdf (accessed 12 August 2010).

TIANNA FERRER, A. (2010) The impact of the Bologna Process in Ibero-America: prospects and challenges. European Journal of Education, 45, pp. 601-611.

TODD, M., BANNISTER, P. \& CLEGG, S. (2004). Independent inquiry and the undergraduate dissertation: perceptions and experiences of final-year social sciences students. Assessment and Evaluation in Higher Education, 29, pp. 335-355.

UNIVERSITY OF LIMERICK (2003) Final Year Project Handbook. Available online at: $\quad$ www.mic.ul.ie/foi/FYP\%20Revised\%20Handbook\%20V.5\%2013.02.03.htm (accessed 10 August 2010).

VITNER, G. \& ROZENES, S. (2009) Final-year projects as a major element in the IE curriculum. European Journal of Engineering Education, 34, pp. 587-592.

WEBSTER, F., PEPPER, D., \& JENKINS, A. (2000) Assessing the Undergraduate Dissertation. Assessment \& Evaluation in Higher Education, 25, pp. 71-80.

WEINERT, F.E. (2001). Concept of Competence. A conceptual clarification. En D. Rychen y L. Salganik (Eds) Defining and selecting key competencies (pp.45-66). (Kirkland, Huber-Hogrefe Publishers). 
WOOLF, H. (2004) Assessment criteria: reflections on current practices. Assessment and Evaluation in Higher Education, 29, pp. 479-493. 